EXTENDED REPORT

\title{
Increased $C$ reactive protein in response to acute stress in patients with rheumatoid arthritis
}

\author{
J J C S Veldhuiizen van Zanten, C Ring, D Carroll, G D Kitas
}

See end of article for authors' affiliations

....................

Correspondence to:

Dr J J C S Veldhuiizen van

Zanten, School of Sport and Exercise Sciences,

University of Birmingham Birmingham B15 2T, UK; veldhuij@bham.ac.uk

Accepted 7 February 2005

Published Online First

11 February 2005

Ann Rheum Dis 2005;64:1299-1304. doi: 10.1136/ard.2004.032151

Objective: To assess the effects of acute stress on inflammatory, haemostatic, rheological, and haemodynamic activity in patients with rheumatoid arthritis (RA) in comparison with patients with osteoarthritis (OA).

Methods: 21 patients with RA and 10 with OA underwent a brief mental stress task while standing. Inflammatory, haemostatic, rheological, and haemodynamic variables were measured at baseline, during the task, and at recovery.

Results: At baseline, erythrocyte sedimentation rate and fibrinogen were higher in RA than OA. White blood cell count, fibrinogen, blood pressure, and pulse rate increased, whereas prothrombin time and plasma volume decreased during the task in both patient groups. The stress task increased $\mathrm{C}$ reactive protein (CRP) only in patients with RA, and more specifically in those patients with RA with high disease activity.

Conclusions: The increase in the inflammatory marker CRP, which was specific to patients with RA, combined with the haemostatic, rheological, and haemodynamic reactions to the stress task, over and above the already high baseline levels, could underlie the increased risk for myocardial infarction in this vulnerable patient group.

M yocardial infarction (MI) arises from the coincidence of a chronic process-namely, the gradual building up of an atherosclerotic plaque in the vessel wall, and an acute process-namely, the rupture of this plaque and formation of a thrombus. ${ }^{1}$ Evidence implicates inflammation in both processes. ${ }^{1-4}$ There is an association between higher levels of inflammatory markers, such as $\mathrm{C}$ reactive protein (CRP), and the prevalence of MI. ${ }^{5}$ The presence of inflammatory molecules (for example, CRP, cytokines) in plaques renders them more vulnerable to rupture. ${ }^{4}$ It has also been shown that levels of CRP are raised after MI and that the greater the rise the poorer the prognosis.'

Psychologically stressful events have been considered to be precursors of MI. $^{67}$ Almost half of surviving patients attributed their MI to an environmental or behavioural trigger, such as episodes of emotional distress or sudden changes in posture. ${ }^{89}$ The question arises, however, as to how exposure to stress might precipitate MI. Recently, it has been suggested that inflammatory responses to acute mental stress render the plaque unstable and prone to rupture. ${ }^{10}$ It is well established that acute psychological stress elicits increases in arterial blood pressure and changes in blood rheology, such as decreases in plasma volume and increases in blood viscosity. ${ }^{11}$ The consequent increase in shear stress may lead to plaque disruption. ${ }^{2}{ }^{4}$ Haemostatic reactions to mental stress, indicating activation of the coagulation cascade, have also been reported. ${ }^{12}$ Thus, if a plaque were to rupture during mental stress and expose its thrombogenic contents to the procoagulant milieu, clot formation would be rapidly promoted. ${ }^{212}$

Rheumatoid arthritis (RA) is a chronic inflammatory musculoskeletal disease, with predominant symptoms of pain, stiffness, and swelling of joints. ${ }^{13}$ Patients with RA have a higher all-cause mortality rate than control groups matched for age and sex. ${ }^{14}$ It is now recognised that patients with RA are at increased risk for acute cardiovascular events, such as MI, compared with the general population. ${ }^{14}$ Indeed, the most common cause of death in RA is cardiovascular disease, accounting for more than $50 \%$ of the mortality. ${ }^{15}$ Patients with RA also have a higher prevalence of acute cardiovascular events than patients with osteoarthritis (OA), a joint disease not characterised by systemic inflammation. ${ }^{15}$ In addition, patients with RA are more likely to experience silent ischaemia during 24 hour Holter recording ${ }^{16}$ and have higher rates of ischaemia measured by myocardial perfusion imaging ${ }^{17}$ than patients with OA.

Even though there is convincing evidence that RA is characterised by an increased risk for acute cardiovascular events, the underlying pathways remain to be determined. The most likely explanation is that the inflammation associated with RA has an impact on the vasculature. ${ }^{18}$ Epidemiological studies provide indirect support; there is an association in patients with RA between high resting levels of inflammatory markers, such as CRP and erythrocyte sedimentation rate (ESR), and with both the incidence of acute cardiovascular events ${ }^{19}$ and the prevalence of carotid artery plaques. ${ }^{20}$

Laboratory stress models have been used to explore mechanisms underlying triggering of MI. Little attention has been paid to the reactions of patients with RA to exposure to acute stress, although interleukin 6 was found to be raised in anticipation of a stressful operation in patients with RA but not in patients with OA. ${ }^{21}$ However, there has yet to be a detailed examination of cardiovascular reactions of patients with RA to a standard laboratory stress task. Thus, the present study aimed at comparing the cardiovascular reactions of patients with RA and OA to a combined mental and postural stress task. OA was used as a control group because although it is not characterised by a significant systemic inflammatory component, it has several symptoms

Abbreviations: ANCOVA, analysis of covariance; CRP, $C$ reactive protein; DAS, Disease Activity Score; DBP, diastolic blood pressure; ESR, erythrocyte sedimentation rate; MANCOVA, multivariate analysis of covariance; $\mathrm{MI}$, myocardial infarction; OA, osteoarthritis; RA, rheumatoid arthritis; SBP, systolic blood pressure; WBC, white blood cell(s) 
in common with RA (for example, joint pain and stiffness) and may also lead to reduced physical activity, deconditioning, and disability. It was hypothesised that patients with RA would have exaggerated inflammatory, haemostatic, rheological, and haemodynamic reactions compared with patients with OA.

\section{PATIENTS AND METHODS \\ Patients}

Patients were recruited from outpatient rheumatology clinics of the Dudley Group of Hospitals, United Kingdom. Patients had to be able to stand for 15 minutes, but there was no exclusion based on age, sex, drugs used, disease activity or severity, or comorbidity, other than previously confirmed acute coronary syndrome, diabetes mellitus, or serious psychiatric disease. In all, 21 patients with RA and 10 patients with OA were examined. The patients with RA met the retrospective application of the 1987 revised criteria of the American College of Rheumatology. ${ }^{22}$ Their mean (SD) Disease Activity Score (DAS28), ${ }^{23}$ calculated using the number of swollen joints, number of tender joints, ESR, and general health rating, was 4.57 (1.11). Patients abstained from caffeine for 2 hours and from food and smoking for 1 hour before stress testing. For ethical reasons, their drug treatment regimens were not interrupted: analgesics $(76 \%$ RA, 30\% OA), disease modifying antirheumatic drugs ( $81 \%$ RA), non-steroidal anti-inflammatory drugs (14\% RA, 10\% OA), cyclo-oxygenase-2 inhibitors (29\% RA), anti-tumour necrosis factor (19\% RA), steroids (29\% RA). All patients gave informed consent and the study was approved by the hospital ethics committee.

\section{Physiological measurements Blood sampling}

An 18 gauge Teflon catheter (Venflon; Becton Dickinson) was introduced into an antecubital vein and connected to a three way stopcock (Sims Portex). On each draw, the first $3 \mathrm{ml}$ of blood was collected in a syringe and discarded, and then $23 \mathrm{ml}$ of blood was collected in one syringe. After each draw, $3 \mathrm{ml}$ of $0.9 \%$ saline (Baxter) was infused to maintain the catheter patent. The drawn blood was immediately transferred into collection tubes. A $4 \mathrm{ml}$ tube containing separation gel (Vacuette, Greiner Bio-One) was used for analysing CRP by the immunoturbidity method. A $4 \mathrm{ml}$ tube containing potassium ethylenediaminetetraacetic acid (EDTA K2E, Vacuette, Greiner Bio-One) was used to perform a full blood count using an Advia 120 Hematology system (Bayer), that yielded a white blood cell (WBC) count, packed cell volume, and haemoglobin. The plasma volume was estimated from the packed cell volume and haemoglobin using Dill and Costill's formula. ${ }^{24}$ A $5 \mathrm{ml}$ tube containing buffered sodium citrate (Seditainer, Becton Dickinson) was used for ESR measurement. Finally, a $4 \mathrm{ml}$ tube containing sodium citrate (3.2\%, Vacuette, Greiner Bio-One) was used to measure fibrinogen and the prothrombin time using an ACL Futura (Instrumentation Laboratory).

\section{Haemodynamic measures}

Systolic blood pressure (SBP), diastolic blood pressure (DBP), and pulse rate were measured using a blood pressure monitor (Omron HEM-705CP), recommended by the British Hypertension Society, ${ }^{25}$ and a brachial cuff.

\section{Stress task}

The stress task was a paced auditory serial addition test, ${ }^{26}$ performed while patients were tilted to a head-up-tilt of 64 degrees. This position elicits $90 \%$ of the cardiovascular response while avoiding the discomfort associated with standing upright on a tilt table. ${ }^{27}$ For the mental stress task,
Table 1 Patient characteristics of the patients with RA and $\mathrm{OA}$

\begin{tabular}{lll}
\hline Characteristics & $\begin{array}{l}\text { RA } \\
(\mathbf{n = 2 1 )}\end{array}$ & $\begin{array}{l}\text { OA } \\
(\mathbf{n}=10)\end{array}$ \\
\hline Age (years) & $57(11)$ & $47(11)$ \\
Sex (\% women) & 86 & 60 \\
Married or cohabiting (\%) & 90 & 100 \\
Employed (\%) & 24 & 80 \\
Education (years) & $11(2)$ & $12(3)$ \\
Current or ex-smoker (\%) & 52 & 80 \\
Body mass index (kg/m $\left.{ }^{2}\right)$ & $29.0(5.1)$ & $25.2(2.6)$ \\
Disease duration (years) & $12(11)$ & $8(2)$ \\
\hline
\end{tabular}

Values are the means (SD) for continuous variables and percentages for categorical variables.

patients were presented with a series of single digit numbers and required to add each number to the number presented next. Thus, they had to perform simple addition and also remember the latter of two numbers presented for subsequent addition to the next number. Numbers were delivered using an audio tape player and patients had to call out their answers, which were ostentatiously recorded by the experimenter. The task consisted of four consecutive 2 minute periods of 30, 34, 40, and 48 numbers at presentation rates of $4.0,3.5,3.0$, and $2.5 \mathrm{~s}$, respectively. In each block of 10 numbers, patients received an aversive noise burst either following their first incorrect response (a wrong answer, a late response, or no answer), or, if they had not responded incorrectly, at the end of the block. These demands (increasing time pressure, social evaluation, and punishment) have been found to increase the provocativeness of the task. $^{28}$ The combination of mental stress and postural stress has been shown to elicit substantial rheological reactions. ${ }^{29}$

\section{Procedure}

Patients completed one 3 hour session, starting between 900 am and $100 \mathrm{pm}$. On arrival, the procedure was explained and demographic information collected. Next, the catheter was inserted and the blood pressure cuff secured. Patients lay semirecumbent on a bed, and an initial familiarising blood pressure measure was taken. They completed a 20 minute formal rest period (baseline) during which they lay semirecumbent and remained quiet. Patients were then asked to step on the tilt table, which was tilted to 64 degrees. Ten practice trials of the stress task were undertaken, followed by the 8 minute task. On task completion, patients again lay semirecumbent on the bed for a 30 minute recovery period.

Blood pressure readings were obtained at the start of minutes $14,16,18$, and 20 of the resting baseline, minutes 2 , 4,6 , and 8 of the stress task, and minutes $24,26,28$, and 30 of the recovery. Blood was taken immediately after each period-that is, baseline, task (while on the tilt table), and recovery.

\section{Data reduction and analysis}

SBP, DBP, and pulse rate measurements during baseline, task, and recovery were each averaged to yield a mean baseline, task, and recovery value. Analysis of variance and $\chi^{2}$ were used to compare the demographic and other characteristics of the two patient groups (table 1). Patients with RA were older than patients with OA, $F(1,29)=5.63, \mathrm{p}<0.05$, $\eta^{2}=0.162$, and were less likely to be in paid employment, $\chi^{2}$ $(1)=11.98, p<0.01$. Given the age difference between the patient groups, two group (RA, OA) analyses of covariance (ANCOVA), with age as the covariate, were performed on the baseline physiological data. The effects of the acute stress task were examined using separate group $($ RA, OA) $\times$ period (baseline, task, recovery) repeated measures multivariate 
Table 2 Mean (SD) age adjusted baseline measures for patients with RA and OA

\begin{tabular}{|c|c|c|c|c|c|}
\hline Baseline measures & $\begin{array}{l}\text { RA } \\
(n=21)\end{array}$ & $\begin{array}{l}O A \\
(n=10)\end{array}$ & F Value & p Value & $\eta^{2}$ \\
\hline CRP (mg/l) & $10.4(13.4)$ & $5.7(13.9)$ & 0.73 & 0.40 & 0.025 \\
\hline White blood cells $\left(\times 10^{9} / \mathrm{l}\right)$ & $7.7(2.2)$ & $6.3(2.2)$ & 2.35 & 0.14 & 0.077 \\
\hline ESR (mm/1 st h) & $27.5(16.7)$ & $12.8(19.1)$ & 4.12 & 0.05 & 0.142 \\
\hline Fibrinogen (g/l) & $4.1(1.0)$ & $3.1(1.0)$ & 5.64 & 0.03 & 0.173 \\
\hline Prothrombin time (s) & $13.4(0.8)$ & $13.0(0.8)$ & 1.59 & 0.22 & 0.059 \\
\hline Plasma volume (\%) & $60.2(4.0)$ & $61.9(4.1)$ & 1.05 & 0.32 & 0.036 \\
\hline Systolic blood pressure $(\mathrm{mm} \mathrm{Hg})$ & $137(16.3)$ & $129(16.8)$ & 1.41 & 0.24 & 0.048 \\
\hline Diastolic blood pressure $(\mathrm{mm} \mathrm{Hg})$ & $84(10.4)$ & $78(10.8)$ & 2.01 & 0.17 & 0.067 \\
\hline Pulse rate (bpm) & $66(10.4)$ & $64(10.7)$ & 0.20 & 0.66 & 0.007 \\
\hline
\end{tabular}

analysis of covariance (MANCOVA), with age as the covariate. A measure of effect size (eta squared, $\eta^{2}$ ) is reported throughout and, where appropriate, Newman-Keuls post hoc analyses were conducted. Occasional missing data are reflected in variations in the degrees of freedom.

\section{RESULTS}

Baseline inflammatory, haemostatic, rheological, and haemodynamic measures

Table 2 summarises the age adjusted means of the baseline physiological measures for the two patient groups. ANCOVA showed that patients with RA had a higher ESR and fibrinogen than patients with OA.

\section{Inflammatory reactions to stress}

Figures $1 \mathrm{~A}$ and B show the baseline, task, and recovery age adjusted data for the inflammatory measures, CRP and WBC. Group (RA, OA) $\times$ period (baseline, task, recovery) MANCOVA, with age as the covariate, showed no main effects for period or group. However, there was a significant group $\times$ period interaction for $\mathrm{CRP}, F(2,21)=6.69, \mathrm{p}<0.01$, $\eta^{2}=0.389$. Supplementary analyses confirmed the trend shown in fig lA: CRP increases after the stress task in patients with RA, $F(2,14)=10.49, \mathrm{p}<0.01, \eta^{2}=0.600$, but
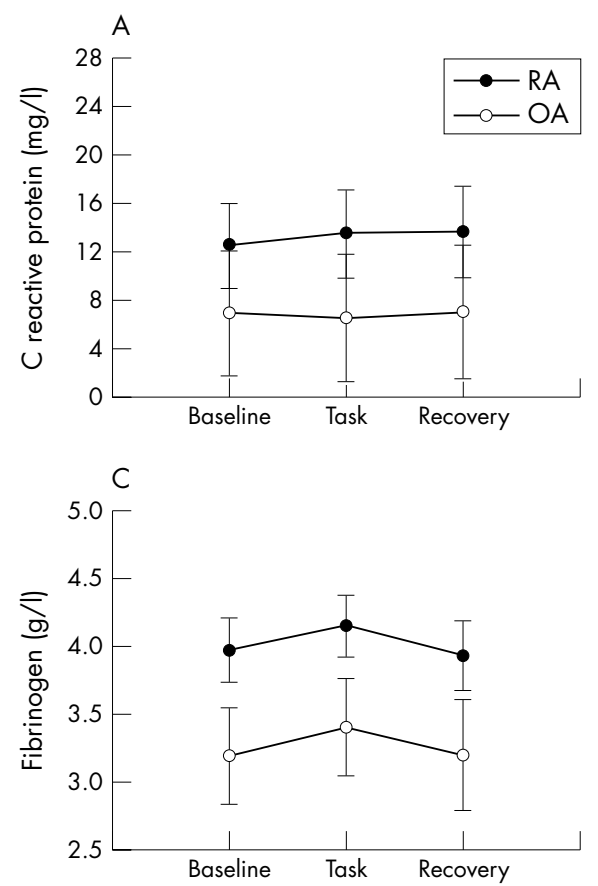

not in patients with OA. There was a period effect for WBC, $F(2,24)=10.10, \mathrm{p}<0.01, \eta^{2}=0.457$; post hoc analyses disclosed that in both patient groups WBC increased with the stress task. WBC decreased again during recovery, but still remained raised relative to baseline levels. There was no

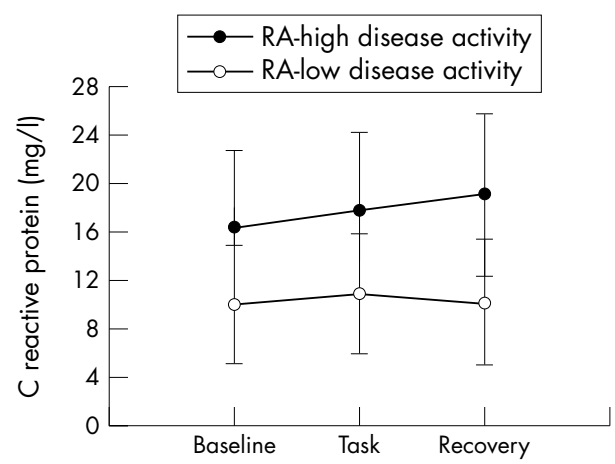

Figure 2 Mean age adjusted (SE) CRP during baseline, stress task, and recovery in patients with RA with high disease activity and with low disease activity.
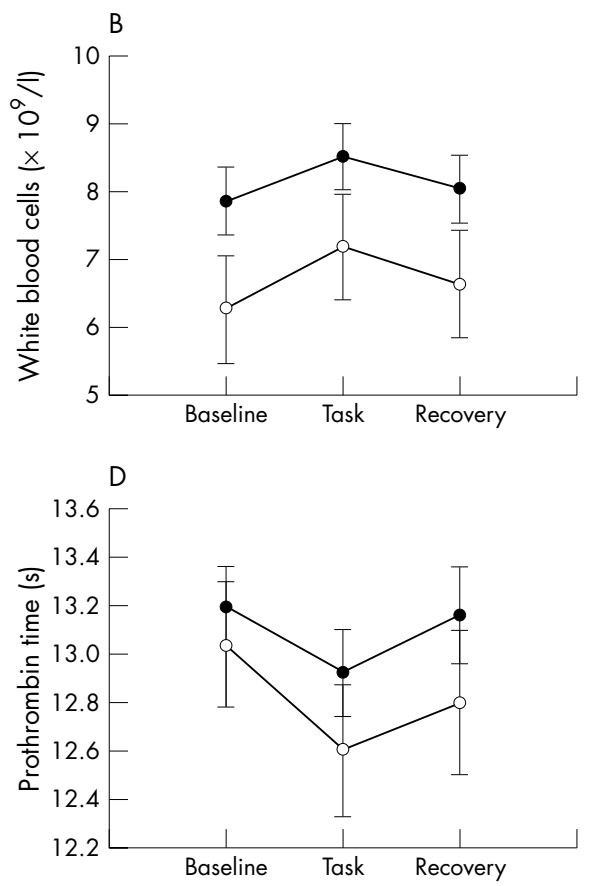

Figure 1 Mean age adjusted (SE) CRP (A), WBC (B), fibrinogen (C), and prothrombin time (D) during baseline, stress task, and recovery in patients with RA and OA. 
group or group $\times$ period interaction effect for WBC. No effects emerged for ESR.

The CRP increase was examined further by allocating the patients with RA to a high disease or a low disease activity group on the basis of their DAS28 score. A DAS28 of 4.4 is the average DAS in clinical trials of disease modifying antirheumatic drugs, which require patients with active RA (Professor DPM Symmons, personal communication). Therefore patients with DAS $<4.4(\mathrm{n}=11)$ are not in remission and still have some mild to moderate inflammatory activity. Patients with DAS $>4.4(\mathrm{n}=10)$ have moderate to severe inflammatory activity. MANCOVA now showed a period effect for CRP, $F(2,20)=4.27, \mathrm{p}<0.05, \eta^{2}=0.299$, as well as a group (high disease activity RA, low disease activity RA, $\mathrm{OA}) \times$ period interaction effect, $F(4,40)=4.13, \mathrm{p}<0.01$, $\eta^{2}=0.548$. Figure 2 summarises these data. Supplementary analyses indicated that CRP increased significantly in response to the stress task only in the patients with RA with high disease activity, $F(2,5)=6.44, p<0.05, \eta^{2}=0.720$. Finally, it should be noted that neither baseline CRP nor CRP reactivity were accounted for by differences in drug treatment regimens.

\section{Haemostatic reactions to stress}

Figures $\mathrm{IC}$ and D display the summary age adjusted data for fibrinogen and prothrombin time. Significant period effects emerged for both fibrinogen, $F(2,23)=8.50, \mathrm{p}<0.01$, $\eta^{2}=0.425$, and prothrombin time, $F(2,23)=36.19$, $\mathrm{p}<0.001, \eta^{2}=0.759$. Post hoc analyses indicated that fibrinogen increased, whereas prothrombin time shortened in response to the task. The prothrombin time lengthened in recovery, but remaining quicker than at baseline. The overall group effect for fibrinogen shown in fig IC was not significant, $F(1,23)=2.77, \mathrm{p}=0.11, \eta^{2}=0.107$.

\section{Rheological reactions to stress}

Figure $3 \mathrm{~A}$ presents the summary plasma volume data, adjusted for age. A period effect emerged, $F(2,24)=58.22$, $\mathrm{p}<0.001, \eta^{2}=0.829$; post hoc analyses indicated that the
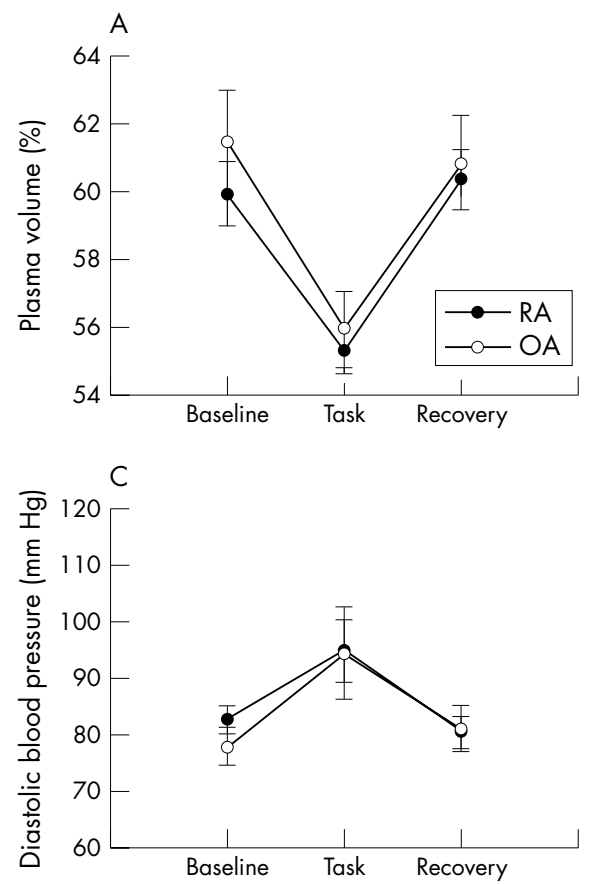

plasma volume decreased with stress and returned to baseline levels by the end of the recovery. There were neither group nor group $\times$ period interaction effects.

\section{Haemodynamic reactions to stress}

Figures 3B, C, and D present the summary age adjusted data for blood pressure and pulse rate. Significant period effects were found for SBP, $F(2,26)=11.30, \mathrm{p}<0.001, \eta^{2}=0.465$, DBP, $F(2,26)=4.89, \mathrm{p}<0.05, \eta^{2}=0.273$, and pulse rate, $F(2$, 26) $=24.98, \mathrm{p}<0.001, \eta^{2}=0.658$. Blood pressure and pulse rate increased from baseline to task and returned to basal levels during recovery. No group or group $\times$ period interaction effects were found.

\section{DISCUSSION}

Acute mental stress combined with postural stress increased CRP only in patients with RA and specifically in those patients with RA with high disease activity. The observation that CRP did not change with stress in patients with OA or patients with RA with low disease activity is in agreement with recent findings that CRP was not increased by stress in healthy middle aged subjects ${ }^{30}$ and students (Ring, PhD, unpublished data, 2002). Thus, stress-induced increases in CRP may be a particular characteristic of patients with RA with high disease activity. CRP is a well established risk factor for MI. ${ }^{5}$ Recently, it has been suggested that CRP is more than merely a risk factor, acting as a causal agent facilitating thrombotic occlusion and atherosclerosis. ${ }^{31}$ Thus, the stress-induced increase in CRP in patients with RA with high disease activity over and above their high baseline levels might contribute to their increased risk for MI.

The increase in CRP during inflammation is the result of an increase in the number of cells producing $\mathrm{CRP},{ }^{32}$ as well as an increase in CRP secretion rate. ${ }^{33}$ Not all the CRP produced by the liver is released directly into the blood; small amounts are bound to a hepatic carboxylesterase in the endoplasmatic reticulum. $^{34}$ During inflammation, however, this specific binding of CRP is diminished, resulting in more efficient secretion. $^{33}{ }^{34}$ The patients with RA in our study were
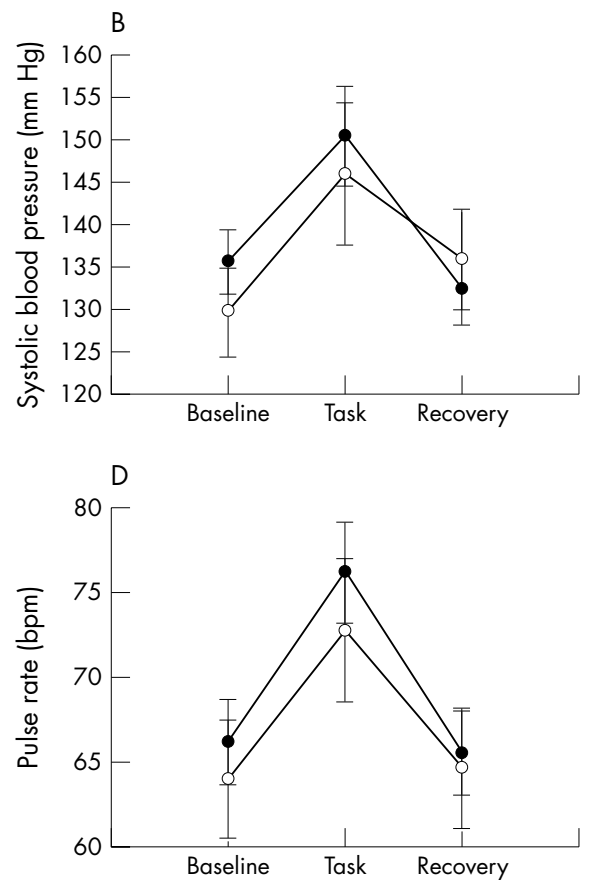

Figure 3 Mean age adjusted (SE) plasma volume (A), SBP (B), DBP (C), and pulse rate (D) during baseline, stress task, and recovery in patients with RA and OA. 
characterised by more inflammation, as reflected by higher baseline ESR (+115\%) and, although not significant, presumably due to the larger interindividual variability, CRP $(+82 \%)$ and WBC $(+22 \%)$, than in patients with OA. Possibly, owing to their higher systemic inflammation, both CRP production and secretion were more efficient, leading to an immediate rise in serum levels with stress in the patients with RA with high disease activity.

Although CRP has traditionally been thought to be produced exclusively by hepatic cells, there is increasing evidence for other sources of CRP, such as macrophages, lymphocytes, normal vascular tissue, and atherosclerotic plaques. ${ }^{35}$ Patients with RA have increased rates of atherosclerosis $^{36}$; hence, the production of CRP from atherosclerotic plaques cannot be disregarded in this patient group. This alternative source of CRP may provide another explanation for the stress-induced CRP increases in patients with RA.

No group differences in stress response were found for the other inflammatory markers; ESR did not change in either group, whereas WBC increased similarly in both patient groups, a finding that has been reported previously in both healthy participants as well as patients with RA. ${ }^{37}$ However, at baseline, levels of inflammatory markers were higher in patients with RA than in those with OA and, consequently, were higher during stress (see fig 1). The current data show that the stress task elicited an inflammatory response in both patient groups, but also emphasise a degree of specificity in patients with RA with high disease activity. Disease activity, as measured by high levels of inflammatory markers, has been associated with an increased risk for cardiovascular events and mortality. ${ }^{198}$ Thus, possibly, patients with RA with high disease activity are more vulnerable to cardiac events because of their increased inflammatory activity during rest and stress.

The stress task also produced changes in haemostatic, rheological, and haemodynamic measures, which were similar in patients with RA and OA. Collectively, these changes might lead to a hypercoaguable state and an increase in shear stress on the vessel wall, both of which have been implicated as triggers for atherosclerotic plaque rupture. ${ }^{24}$ Patients with RA, however, had higher baseline levels of fibrinogen. Thus, even though the reactions to the stress task were similar in both patient groups, absolute fibrinogen levels were higher during the task in patients with RA than in patients with OA. Moreover, categorising the patients with RA on the basis of disease activity indicated that patients with RA with high disease activity displayed particularly high fibrinogen values. Thus, it is possible that in patients with high disease activity, stress serves to raise the already high fibrinogen values to levels that further increase patients' susceptibility to thrombogenic events.

An acute cardiovascular event is the result of several mechanisms, such as increased inflammation and coagulation. Although many individual risk factors have been recognised, it has been suggested that a cardiovascular risk profile, incorporating several factors, is the best method for characterising risk for acute events. ${ }^{39}$ At baseline, patients with RA displayed high levels of several individual risk factors, such as ESR and fibrinogen, and a further increase was seen in most measures during stress. Thus, the baseline profile appears to place the patients with RA at greater risk than the patients with OA, with an even less favourable risk profile evident during stress.

In conclusion, acute stress elicited increases in inflammatory, haemostatic, rheological, and haemodynamic measures in patients with RA and OA. However, there was also a stressinduced increase in CRP, which was specific to patients with RA with high disease activity. This inflammatory reaction to stress, which was exacerbated in patients with
RA, superimposed on their higher baseline levels, might contribute to the increased risk for MI in this susceptible patient group. These findings also imply that effective disease management, in addition to controlling the inflammatory activity, may also need to include training in stress management and coping strategies.

\section{ACKNOWLEDGEMENTS}

Part of this work was funded by the Dudley Group of Hospitals R \& D Directorate.

\section{Authors' affiliations}

J J C S Veldhuijzen van Zanten, C Ring, D Carroll, School of Sport and Exercise Sciences, University of Birmingham, UK

J J C S Veldhuijzen van Zanten, G D Kitas, Department of Rheumatology, Dudley Group of Hospitals NHS Trust, UK G D Kitas, Department of Rheumatology, Division of Immunity and Infection, School of Medicine, University of Birmingham, UK

The study was approved by the Dudley Research Ethics Committee.

None of the authors have a competing interest to disclose.

\section{REFERENCES}

1 Libby P, Ridker PM, Maseri A. Inflammation and atherosclerosis. Circulation 2002; 105: 1135-43

2 Worthley SG, Osende JI, Helft G, Badimon JJ, Fuster V. Coronary artery disease: pathogenesis and acute coronary syndromes. Mt Sinai J Med $2001 ; 68: 167-81$

3 Ross R. Atherosclerosis - an inflammatory disease. N Engl J Med 1999;340:115-26.

4 Falk E, Shah PK, Fuster V. Coronary plaque disruption. Circulation 1995;92:657-71.

5 Ridker PM. High-sensitivity C-reactive protein and cardiovascular risk: rationale for screening and primary prevention. Am J Cardiol 2003;92:17-22.

6 Carroll D, Ebrahim S, Tilling K, Macleod J, Davey Smith G. Admissions for myocardial infarction and World Cup football: database survey. BMJ 2002;325: 1439-42

7 Kloner RA, Leor J, Poole WK, Perritt R. Population-based analysis of the effect of the Northridge earthquake on cardiac death in Los Angeles County, California. J Am Coll Cardiol 1997;30:1174-80

8 Tofler GH, Stone PH, Maclure M, Edelman E, Davis VG, Robertson T, et al. Analysis of possible triggers of acute myocardial infarction (the MILIS study). Am J Cardiol 1990;66:22-7.

9 Smith M, Little WC. Potential precipitating factors of the onset of myocardial infarction. Am J Med Sci 1992;303:141-4.

10 Kop WJ. The integration of cardiovascular behavioral medicine and psychoneuroimmunology: new developments based on converging research fields. Brain Behav Immun 2003;17:233-7.

11 Allen MT, Patterson SM. Hemoconcentration and stress: a review of physiological mechanisms and relevance for cardiovascular disease risk. Biol Psychol 1995;41:1-27.

12 Von Känel R, Mills PJ, Fainman C, Dimsdale JE. Effects of psychological stress and psychiatry disorders on blood coagulation and fibrinolysis: a biobehavioral pathway to coronary artery disease? Psychosom Med 2001;63:531-44.

13 Lee DM, Weinblatt ME. Rheumatoid arthritis. Lancet 2001;358:903-11.

14 Kitas GD, Erb N. Tackling ischaemic heart disease in rheumatoid arthritis. Rheumatology (Oxford) 2003;42:607-13.

15 DeMaria AN. Relative risk of cardiovascular events in patients with rheumatoid arthritis. Am J Cardiol 2002;89(suppl):33-8D.

16 Wislowska M, Sypula S, Kowalik I. Echocardiographic findings, 24-hour electrocardiographic Holter monitoring in patients with rheumatoid arthritis according to Steinbrocker's criteria, functional index, value of Waaler-Rose titre and duration of disease. Clin Rheumatol 1998;17:369-77.

17 Banks M, Flint J, Bacon PA, Kitas GD. Rheumatoid arthritis is an independent risk factor for ischaemic heat disease [abstract]. Arthritis Rheum 2000;43(suppl 9):S385.

18 Sattar N, McCarey DW, Capell H, Mclnnes IB. Explaining how "high-grade" systemic inflammation accelerates vascular risk in rheumatoid arthritis. Circulation 2003; 108:2957-63.

19 Wållberg-Jonsson S, Johansson H, Öhman M-L, Rantapää-Dahlqvist S. Extent of inflammation predicts cardiovascular disease and overall mortality in seropositive rheumatoid arthritis. A retrospective cohort study from disease onset. J Rheumatol 1999;26:2562-71.

20 Del Rincòn I, Williams K, Stern MP, Freeman GL, O'Leary DH, Escalante A. Association between carotid atherosclerosis and markers of inflammation in rheumatoid arthritis patients and healthy subjects. Arthritis Rheum 2003;48: 1833-40.

21 Hirano D, Nagashima M, Ogawa R, Yoshino S. Serum levels of interleukin 6 and stress related substances indicate mental stress condition in patients with rheumatoid arthritis. J Rheumatol 2001;28:490-5. 
22 Arnett FC, Edworthy SM, Bloch DA, McShane DJ, Fries JF, Cooper NS, et al. The American Rheumatism Association 1987 revised criteria for the classification of rheumatoid arthritis. Arthritis Rheum 1988:31:315-24.

23 van der Heijde DM, van ' $t$ Hof MA, van Riel PL, Theunisse LA, Lubberts EW Van Leeuwen MA, et al. Judging disease activity in clinical practice in rheumatoid arthritis: first step in the development of a disease activity score. Ann Rheum Dis 1990;49:916-20.

24 Dill DB, Costill DL. Calculations of percentage changes in volumes of blood, plasma, and red cells in dehydration. J Appl Physiol 1974; 37:247-8

25 O'Brien E, Waeber B, Parati G, Staessen J, Myers MG. Blood pressure measuring devices: recommendations of the European Society of Hypertension. BMJ 2001;322:531-6.

26 Gronwall DM. Paced auditory serial-addition task: a measure of recovery from concussion. Percept Motor Skills 1977;44:367-73.

27 Gaver OH, Thron HL. Postural changes in the circulation. In:American Physiological Society Handbook of pysiology.Section 2, Volume III. Circulation. Washington DC: Williams and Wilkins, 1965:2409-39.

28 Veldhuijzen van Zanten JJCS, Ring C, Burns VE, Edwards KM, Drayson M, Carroll D. Mental stress-induced hemoconcentration: sex differences and mechanisms. Psychophysiology 2004;41:541-51.

29 Veldhuijzen van Zanten JJCS, Thrall G, Wasche D, Carroll D, Ring C. The influence of hydration status on stress-induced hemoconcentration. Psychophysiology 2005;42:98-107.

30 Steptoe A, Willemsen G, Owen N, Flower L, Mohamed-Ali V. Acute menta stress elicits delayed increases in circulating inflammatory cytokine levels. Clin Sci (Lond) 2001;101:185-92.
31 Paul A, Ko KWS, Li L, Yechoor V, McCrory MA, Szalai AJ, et al. C-reactive protein accelerates the progression of atherosclerosis in apolipoprotein $\mathrm{E}$ deficient mice. Circulation 2004; 109:647-55.

32 Kushner I, Feldmann G. Control of the acute phase response. Demonstration of $C$-reactive protein synthesis and secretion by hepatocytes during acute inflammation in the rabbit. J Exp Med 1978;148:466-77.

33 Macintyre SS, Kushner I, Samols D. Secretion of C-reactive protein becomes more efficient during the course of the acute phase response. J Biol Chem 1985;260:4169-73.

34 Yue CC, Muller-Greven J, Dailey P, Lozanski G, Anderson V, Macintyre S. Identification of a C-reactive protein binding site in two hepatic carboxylesterases capable of retaining C-reactive protein within the endoplasmic reticulum. J Biol Chem 1996;271:22245-50.

35 Jabs WJ, Theissing E, Nitschke M, Bechtel JF, Duchrow M, Mohamed S, et al. Local generation of $C$-reactive protein in diseased coronary artery venous bypass grafts and normal vascular tissue. Circulation 2003;108:1428-31.

36 Bacon PA, Stevens RJ, Carruthers DM, Young SP, Kitas GD. Accelerated atherogenesis in autoimmune rheumatic diseases. Autoimmun Rev 2002; 1:338-47.

37 Geenen R, Godaert GL, Heijnen CJ, Vianen ME, Wenting MJ, Nederhoff MG, et al. Experimentally induced stress in rheumatoid arthritis of recent onset: effects on peripheral blood lymphocytes. Clin Exp Rheumatol 1998;16:553-9.

38 Wållberg-Jonsson S, Cederfelt M, Rantapää-Dahlqvist S. Hemostatic factors and cardiovascular disease in active rheumatoid arthritis: an 8 year followup and cardiovascular disease in active ritol $2000 ; 27: 71-5$.
study. J Rheumato

39 Cohn JN, Quyyumi AA, Hollenberg NK, Jamerson KA. Surrogate markers for cardiovascular disease: functional markers. Circulation 2004;109/suppl 1):IV31-46.

\section{bmjupdates+}

bmjupdates+ is a unique and free alerting service, designed to keep you up to date with the medical literature that is truly important to your practice.

bmjupdates+ will alert you to important new research and will provide you with the best new evidence concerning important advances in health care, tailored to your medical interests and time demands.

\section{Where does the information come from?}

bmjupdates+ applies an expert critical appraisal filter to over 100 top medical journals A panel of over 2000 physicians find the few 'must read' studies for each area of clinical interest

Sign up to receive your tailored email alerts, searching access and more... www.bmjupdates.com 